\title{
Como estão os resíduos urbanos nas favelas cariocas?
}

\author{
How are municipal waste in the slums of Rio de Janeiro?
}

Adriana Soares de Schueler, Humberto Kzure, Gustavo Badolati Racca

Universidade Federal Rural do Rio de Janeiro (UFRRJ), Seropédica, RJ, Brasil

\section{Resumo}

Comunidades de baixa renda, situadas em encostas ou em locais planos, apresentam sérios problemas de gestão ambiental urbana, sendo a geração, disposição e coleta de resíduos sólidos urbanos um deles. Houve tempo em que o lixo urbano se acumulava nesses espaços pauperizados, pela inexistência de políticas públicas de saneamento. Todavia, a produção de resíduos na cidade contemporânea é resultado do mesmo tipo de consumo que afeta diferentes escalas e contextos socioeconômicos. Desafios como a alta densidade urbana, a falta de espaço para disposição temporária de resíduos e a dificuldade de acesso de caminhões e equipamentos de coleta em áreas de favelas, por exemplo, são permanentes. $O$ fato é que, mesmo com coleta regular, ainda é frequente a presença de focos de disposição irregular de lixo nas favelas da cidade do Rio de Janeiro. As reflexões pretendidas neste artigo buscam, de modo geral, contextualizar a situação da gestão do lixo em nove comunidades de baixa renda no bairro de Jacarepaguá entre os anos de 2014 e 2016. Inicialmente, foi diagnosticada a situação do lixo nesses tecidos urbanos marcados pela informalidade e ilegalidade para, posteriormente, desenvolverem-se alternativas capazes de reduzir a dificuldade de manejo do material e facilitar a sua coleta. Nesse sentido, abre-se uma discussão sobre as ações da esfera pública e do planejamento urbano na elaboração de projetos de urbanização de favelas que visem a melhoria da qualidade de vida dos moradores sob a perspectiva socioambiental e suas articulações com os aspectos socioeconômicos e socioculturais.

Palavras-chave: Gestão ambiental urbana. Gestão de resíduos sólidos urbanos. Planejamento e gestão urbana em favelas. Saneamento. Planejamento urbano.

\section{Abstract}

Low-income communities situated on slopes or flat sites present serious problems of urban environmental management, including the generation, disposal and collection of municipal solid waste. There was a time when the urban waste was accumulated in these very poor spaces due to lack of public sanitation policies. However,

ASS é Arquiteta e Urbanista, Doutora em Engenharia Civil, Professora da Universidade Federal Rural do Rio de Janeiro e do Programa de Pós-graduação em Desenvolvimento Territorial e Políticas Públicas, e-mail: schueler.a@gmail.com HKé Arquiteto e Urbanista, Doutor em Planejamento Urbano, Professor da Universidade Federal Rural do Rio de Janeiro e pesquisador do Programa de Pós-Graduação em Desenvolvimento Territorial e Políticas Públicas, e-mail: humbertokzure@hotmail.com GBR é Arquiteto e Urbanista, Mestre em Urbanismo, Doutorando no Prourb, Universidade Federal do Rio de Janeiro, e-mail: gusracca@gmail.com 
waste production in contemporary cities is the result of the same type of consumption which affects different scales and socioeconomic contexts. Challenges such as high urban density, lack of space for temporary disposal of waste, and difficult access of trucks and collection equipment in slum areas, for example, are persistent. As a matter of fact, despite the regular collection, irregular disposal of garbage is still frequent in the slums of Rio de Janeiro. The reflections in this article seek a general contextualization of the waste management situation in nine low-income communities in Jacarepaguá neighborhood between the years of 2014 and 2016. The situation of garbage collection in these urban places, which are marked by informality and illegality, was initially diagnosed and then alternatives to reduce the difficulty to manage of material and to facilitate its collection were developed. In this sense, we introduce a discussion on the actions of the public sphere and urban planning in the development of slum upgrading projects, aimed at improving the quality of life of the residents from a socio-environmental perspective, and their articulation with socio-economic and socio-cultural aspects.

Keywords: Environmental management. Urban solid waste management. Urban planning/management. Sanitation. Urban design.

\section{Introdução}

Nas cidades brasileiras ainda persistem fisionomias de acentuado abismo social e criticidade ambiental que demonstram, historicamente, o expressivo déficit em infraestrutura urbana, principalmente em ocupações desordenadas como as áreas de favelas. Nesse caso, os parcos investimentos públicos em saneamento ambiental comprovam o grau de vulnerabilidade a que estão submetidas as parcelas mais pobres dos tecidos urbanos. Em pleno século $\mathrm{XX}$, cidades como o Rio de Janeiro, a despeito dos fenômenos espaciais e das mutações que se operam territorialmente, fruto das disfunções urbanas acumuladas a partir das diferentes transformações da produção socioeconômica - com destaque para a industrialização do passado - , ainda convive com incertezas que instigam analistas do mundo sobre a qualidade de vida no espaço urbano. Somam-se a isso muitos estudos técnico-científicos que desafiam o poder público para a provisão de infraestrutura básica. Vale ressaltar, no entanto, que a cidade contemporânea, difusa e repleta de inúmeras contradições, adquiriu contornos expressivos do espetáculo, do consumismo exacerbado e da insegurança, por exemplo. Pode-se afirmar que há certa dicotomia entre as demandas atuais por ampliação e modernização das estruturas funcionais urbanas e o "[...] estágio de inadequação espacial que obriga a otimização da cidade em uma perspectiva de futuro que nega suas matrizes do passado [...]" (Kzure-Cerquera, 2014, p. 32).

É preciso lembrar que o urbanismo, como atestam vários estudos acadêmicos, nasceu da busca pelo saneamento, em decorrência dos impactos ambientais nas principais cidades do século XIX, provocados pelo advento da Revolução Industrial, tendo possibilitado debates relacionados aos aspectos formais e à estrutura econômica e social da urbe. Notadamente, entre as preocupações dos sanitaristas e dos utopistas, à época, os detentores da hegemonia política e econômica dos principais centros urbanos passariam a estabelecer as novas bases de acumulação patrimonial. Nesse sentido, a incessante busca por uma forma definitiva da cidade esteve mais voltada à lucratividade e menos relacionada à saúde urbana.

Da cidade industrial aos dias atuais, o espaço urbano se tornou mais complexo e multifacetado. A cidade contemporânea e globalizada não apenas reflete a intensificação de um sistema heterogêneo de representações políticas, econômicas e socioculturais como também as questões ambientais. A paisagem urbana de hoje revela o quanto a cidade se tornou o lastro que sedimenta o espetáculo do consumo e o quanto tem favorecido a produção de resíduos.

Se, na cidade do final do século XIX e início do XX, os problemas de saúde pública estavam relacionados à emissão de poluentes no ambiente construído, à precariedade da infraestrutura sanitária, aos problemas de mobilidade e ao déficit de moradia, a cidade do século XXI procurou avançar na resolução dessas questões do passado, mas ainda se depara, por exemplo, com o uso inadequado do solo urbano, com elevadas taxas de adensamento populacional e com a criticidade ambiental, na qual os resíduos sólidos urbanos (RSU) representam um dos principais desafios para o planejamento urbano. 
Diante desse contexto, interessa aqui traçar reflexões sobre a urbanização de favelas no Rio de Janeiro e o lixo produzido nessas comunidades de baixa renda. Ressalte-se, no entanto, que a gestão de RSU passou, nos últimos anos, a ser um tema bastante complexo, cujos objetivos são a coleta, o tratamento e a disposição final do lixo gerado pela população urbana. Espera-se que isso seja feito de modo social e ambientalmente satisfatório, usando os meios mais econômicos possíveis.

Não obstante, ainda existe muita resistência para que o processo de tratamento e gestão adequada dos RSU ocorra do modo esperado, principalmente nas favelas, o que desafia as atuações do poder público e dos planejadores urbanos. 0 destino desses resíduos, acrescido a outros problemas sanitários e ambientais, é uma questão que instiga o saneamento urbano. Trata-se, portanto, de matéria inerente à saúde pública, uma vez que a disposição inadequada do lixo urbano provoca a formação de vetores - fontes transmissoras de infecção - , por exemplo. Ao lado disso, há um número crescente de substâncias e materiais identificados como perigosos, e a geração desses resíduos em quantidades expressivas têm exigido soluções mais eficazes e investimentos maiores por parte das administrações públicas e da sociedade civil em geral.

No Brasil, atualmente, são coletados 70 milhões de toneladas de RSU, dispostos em aterros sanitários ou, ainda, em vazadouros, 42\% (Abrelpe, 2015) constituídos espontaneamente em vários municípios, e locais inadequados, desprovidos de planejamento e adequação às normas técnicas vigentes, o que provoca a contaminação do ar, do solo e dos corpos hídricos. Não é raro a presença de descarte em rios urbanos (Abrelpe, 2015) e em pontos específicos nas cidades em que a coleta pública é prejudicada pelas dificuldades de acesso, como ocorre nas favelas cariocas localizadas em áreas de encosta.

A produção de RSU acaba por revelar a interação entre as atividades humanas e o meio ambiente. Os principais fatores que regem sua origem e produção têm vínculos diretos com os processos de industrialização e a maneira como se dá o consumo pela população. Por ser resultado dos rejeitos de inúmeras atividades humanas, apresenta-se bastante heterogêneo e varia de acordo com o espaço geográfico. Ao longo do tempo é possível observar que fatores como o número de habitantes, variações sazonais, condições climáticas, hábitos e costumes da população, nível educacional, poder aquisitivo, segregação na origem, disciplina e controle dos pontos produtores, entre outros, são determinantes para traçar diretrizes de planejamento e regulação específica para RSU. É preciso sublinhar que em época de chuvas fortes o teor de umidade dos RSU tende a crescer. Esse aspecto também pode ser observado com o aumento significativo, em períodos de férias escolares ou festas populares, do consumo de produtos embalados, em vidro, metais e matéria orgânica (Soares \& Mahler, 2012; AbreLpe, 2015). Além disso, o número de folhas de árvores recolhidas durante o outono representa uma contribuição expressiva de RSU.

O conhecimento da composição do lixo ao longo dos anos possibilita verificar alterações nos hábitos e tendências decorrentes das mudanças do poder aquisitivo e de padrões de consumo da população. Permite ainda estabelecer correlações dos resíduos com os estratos socioeconômicos e culturais dos grupos geradores. Há alguns anos atrás observava-se resíduos com maior quantidade de matéria orgânica nas áreas mais pobres da cidade. Atualmente é possível observar nessas mesmas áreas a presença de muitas embalagens de alimentos congelados e resfriados, o que demonstra uma diferença de hábitos que influenciam a nutrição e saúde das pessoas.

Neste estudo, no período entre setembro de 2014 a maio de 2016, foram realizadas incursões a campo em algumas favelas cariocas, no âmbito do Programa Morar Carioca, da Secretaria Municipal de Habitação e Cidadania da Prefeitura da Cidade do Rio de Janeiro - SMHC/PCRJ, visando a realização de levantamentos de dados para a consolidação do diagnóstico de RSU no agrupamento de favelas formado por nove comunidades: Chácara do Tanque, Amigos da Aerobita, Albano n. 252, Caxanga, Ladeira da Reunião, Morro da Reunião, Rua José Braga, Fazenda Mato Alto e Bela Vista do Mato Alto, localizadas no bairro de Jacarepaguá. Uma vez apresentadas as questões concernentes à geração e coleta de RSU, foram elaborados os "cenários" propositivos, como parte integrante da infraestrutura urbana demandada para os referidos assentamentos de baixa renda. Sublinha-se, ainda, que durante os trabalhos de investigação em campo foram identificados pontos de acúmulo de resíduos, a sua classificação e a maneira como era feita a coleta nas áreas pesquisadas, o que permitiu a elaboração das propostas voltadas à melhoria das condições 
sanitárias e ambientais de cada comunidade. Neste trabalho são apresentadas as propostas de projeto para a facilitação da coleta, consequência da gestão dos resíduos sólidos urbanos nas favelas citadas. Com limitações, no entanto, pois consideraram-se os equipamentos de coleta hoje utilizados na limpeza urbana do local, bem como o tipo de gestão praticada, ficando claro, em termos de propostas urbanísticas para o tema, o que é possível ser atualmente alterado.

\section{Alguns olhares sobre a produção de resíduos nas favelas do Rio de Janeiro}

Na cidade do Rio de Janeiro, o espaço-favela já foi amplamente estudado, e essa questão não se esgota. Ao contrário, passados mais de um século desse fenômeno urbano ainda é possível observar e analisar as diferentes transformações físico-espaciais nas favelas cariocas e suas especificidades. De acordo com os estudos de Kzure-Cerquera \& Racca (2014), da histórica disputa pela terra urbana às inúmeras políticas governamentais de remoção, elas se consolidaram territorialmente como alternativa para moradia da população de baixa renda, atingiram patamares elevados de adensamento e representam parte expressiva da paisagem da capital fluminense.

Com frequência, ainda é possível verificar nesse tipo de assentamento precário índices elevados no que tange aos desequilíbrios sociais, culturais e ambientais, bem como relações que se estabelecem com a informalidade e a irregularidade do uso e ocupação do solo, marcados pelo déficit de bens e serviços básicos. Contraditoriamente, é possível verificar certo dinamismo do consumo no interior dessas comunidades, principalmente de eletroeletrônicos, vestuário, alimentos, dentre outros (Abrelpe, 2015). 0 processo acelerado de urbanização tende a aumentar o consumo de bens não duráveis crescendo assim, também, a quantidade de lixo gerado tanto nos grandes quando nos pequenos municípios (Monteiro et al., 2017). Convém lembrar, portanto, que o aquecimento da economia no país entre os anos de 2000 e 2015 favoreceu a formação de novos consumidores, o que levou ao aumento da produção de resíduos na cidade do Rio de Janeiro, inclusive no espaço-favela. Ao lado disto, o aumento considerável na geração de resíduos deve-se ao acesso facilitado a diversos produtos e à obsolescência acelerada, ocasionada pelos avanços tecnológicos constantes, o que leva a população a descartar em maior quantidade e, muitas vezes, precocemente (Phillip et al., 2012).

Se por um lado as favelas cariocas construíram paisagens, identidade e memória particulares ao longo dos anos, por outro uma base econômica surgiu articulada aos meios de produção formal, como apontam muitos estudos socioeconômicos, em decorrência das facilidades de crédito e do aumento dos postos de trabalho com carteira assinada. No entanto, na atual crise econômica, o grau de informalidade e luta individual e coletiva pela sobrevivência tende a se agravar, e também os problemas de saneamento ambiental acumulados há décadas.

Kzure-Cerquera (2010, p. 361) chama atenção para o fato de que o ambiente urbano construído e a lógica de mercado impetrada pelos segmentos mais conservadores das esferas políticas e econômicas, de lucratividade e negociação,

[...] suplantam a emergência por espaços urbanos sustentáveis, ou criam lógicas particulares de uma sustentabilidade a partir de simulacros expressos no desenho urbano ou urbanístico.

Trata-se de uma questão para o saneamento ambiental e os desafios para garantir a saúde pública nas cidades, observando-se que de acordo com o Estatuto da Cidade (Brasil, 2001), a regulação do desenvolvimento urbano no Brasil tem o propósito de evitar e corrigir as distorções do crescimento das cidades e seus efeitos negativos sobre o meio ambiente, bem como garantir o ordenamento e controle do uso do solo, para inibir usos excessivos ou inadequados em relação à infraestrutura urbana. No entanto, cabe sublinhar que esse instrumento urbanístico enfrenta resistências a sua aplicação por parte de vários administradores públicos e setores hegemônicos da economia no país. As áreas mais vulneráveis e de inquestionável criticidade urbana e ambiental permanecem relegadas à segregação sócioespacial. Em linhas gerais, esses espaços de exclusão socioeconômica, sociocultural e socioambiental ainda se mantêm no limiar da informalidade e irregularidade do uso do solo.

Paradoxalmente, muitos investimentos em urbanização de favelas no Rio de Janeiro foram representativos nas duas últimas décadas, com a implantação do programa Favela-Bairro. No entanto, houve aporte de recursos públicos destinados majoritariamente para a infraestrutura (viária, água, 
esgotamento sanitário, drenagem pluvial, iluminação e contenção de encostas), sem se ater às demandas por melhorias habitacionais e tratamento adequado dos RSU. A garantia da regularização fundiária, embora sejam reconhecidas as iniciativas da administração municipal, também não atingiu as metas esperadas. Com o atual programa Morar Carioca criou-se a expectativa de avançar nas políticas de urbanização de todas as favelas até o ano 2020, como contrapartida dos investimentos públicos nos megaeventos - Copa do Mundo 2014 e Olimpíadas 2016. A frustração, porém, tanto para a população residente nas favelas como para os técnicos da esfera pública e privada, é que a urbanização esperada deixou de ser prioridade para a gestão municipal. 0 discurso corrente incorporado pela administração pública fala em sustentabilidade urbana, mas negligencia as ações de infraestrutura nas favelas.

Para compreender a dinâmica sociocultural heterogênea, complexa e estratificada do espaço-favela no Rio de Janeiro cabe sublinhar a emergência de medidas mitigadoras para as questões de saneamento e saúde pública nessas áreas da cidade que representam parte significativa da exclusão social, da insegurança e da violência. Nesse caso, a urbanização para os assentamentos precários necessita associar-se às novas formas de orientação socioeconômica que interferem no cotidiano, exigindo novos procedimentos e enfrentamentos para garantir o direito à cidade. Trata-se de reconhecer as heterogeneidades e os conflitos impostos sobre a dinâmica das favelas como parte das questões urbanas. Para tanto, são imprescindíveis as articulações entre as diversas esferas de governo e a população, principalmente quando envolvem aspectos relativos à questão ambiental como garantia da qualidade de vida do espaço de moradia. Ao lado disto, o resgate das mobilizações sociais voltadas à urbanização de favelas é fundamental para a implementação de políticas públicas que contemplem a inclusão social e territorial como parte do direito à cidadania.

Nessas circunstâncias, interessa aqui enfatizar as discussões contemporâneas em torno dos aspectos geográficos e socioculturais que inscrevem os limites e desafios para compreender a produção de resíduos urbanos, especialmente nas favelas, e, ao mesmo tempo, construir, como parte da urbanização desses espaços pauperizados, procedimentos técnicos para inibir os diferentes tipos de agravo ambiental em decorrência da gestão inadequada do lixo.

\section{Os resíduos descartados no espaço-favela impõem desafios para a urbanização}

Compreender o que são os RSU implica, necessariamente, uma discussão sobre a variedade de constituintes com características diferenciadas que, como observam Soares \& Mahler (2012), se inscrevem espacial e temporalmente de acordo com a escala da cidade e o número de habitantes. Notadamente, a dinâmica socioeconômica do mundo contemporâneo e global tem contribuído para o crescimento da produção de resíduos decorrentes, em grande medida, das alterações no padrão de consumo das classes sociais urbanas. Identificar as mudanças no poder aquisitivo, nos hábitos e no nível educacional da população, por exemplo, são fatores determinantes e desafiadores para o planejamento e a gestão do lixo urbano.

Em 2010 foi publicada a Política Nacional de Resíduos Sólidos - PNRS (Brasil, 2010) dispondo sobre, entre outros, a gestão integrada e o gerenciamento de resíduos sólidos, as responsabilidades dos geradores e do poder público e os instrumentos econômicos aplicáveis. Diversos instrumentos e princípios importantes foram trazidos pela PNRS, na tentativa de deixar o Brasil em patamar similar aos países em desenvolvimento, a saber:

- O princípio da Ecoeficiência, com o objetivo da não geração, redução, reutilização, reciclagem, tratamento e disposição final ambientalmente adequada dos rejeitos, tendo como instrumentos os planos de resíduos sólidos e os acordos setoriais;

- O princípio da Responsabilidade compartilhada pelo ciclo de vida dos produtos, visando a redução do volume e da periculosidade dos resíduos perigosos e tendo como instrumentos os inventários e o sistema declaratório anual de resíduos sólidos;

- 0 princípio do Direito da sociedade à informação e ao controle social, com o objetivo de incentivar a indústria da reciclagem, tendo em vista fomentar o uso de matérias-primas e insumos derivados de materiais recicláveis e reciclados por meio da coleta seletiva, dos sistemas de logística reversa e da responsabilidade compartilhada pelo ciclo de vida dos produtos; 
- O princípio da Cooperação entre as diferentes esferas do poder público, o setor empresarial e demais segmentos da sociedade, buscando a gestão integrada de resíduos sólidos e a articulação entre as diferentes esferas do poder público e com o setor empresarial, com vistas à cooperação técnica e financeira para a gestão integrada de resíduos sólidos, e a capacitação técnica continuada na área de resíduos sólidos, tendo como instrumentos o incentivo à criação e ao desenvolvimento de cooperativas de catadores de materiais reutilizáveis e recicláveis e os incentivos fiscais, financeiros e creditícios, bem como o sistema nacional de informações sobre a gestão dos resíduos sólidos — SINIR.

Países como Alemanha, Dinamarca, Suíça e Bélgica praticamente não enviam mais resíduos para aterros e em alguns países europeus são feitas prestações de contas anuais aos cidadãos quanto aos gastos públicos nas atividades de gestão dos resíduos (Mendez, 2017). Quando a arrecadação supera os gastos, a população tem o retorno das taxas pagas.

No caso das favelas do Rio de Janeiro, mesmo a coleta dos resíduos feita pela Comlurb ${ }^{1}$ na sua forma mais simplificada - resíduos domiciliares, por exemplo ainda não está totalmente resolvida. Localizadas tanto em áreas de várzea como em encostas ou morros, os serviços de limpeza urbana apresentam limitações de ordem geográfica e sociocultural. Nesses espaços, o consumo de produtos orgânicos e industrializados, eletroeletrônicos e materiais de construção civil aumentou substancialmente nas últimas duas décadas, a partir das políticas de crescimento econômico no pais. No entanto, os problemas de descarte nas favelas cariocas, apesar dos programas de urbanização e das iniciativas do poder público para a coleta desses resíduos, ainda constituem uma questão socioambiental a ser enfrentada. Depois de seis anos de sancionada a PNRS, ainda há setores econômicos como os de produção de eletrônicos e seus componentes e de medicamentos cujos acordos para estruturação e implementação dos sistemas de logística reversa sequer foram assinados (SINIR, 2016).

Convém lembrar que os tecidos urbanos das favelas são, em geral, fragilizados pela própria natureza desse tipo de ocupação. As ruelas e servidões, principalmente

\footnotetext{
${ }^{1}$ Comlurb - Companhia Municipal de Limpeza Urbana da Cidade do Rio de Janeiro.
}

as inclinadas, com ou sem pavimento, se constituem como um emaranhado de acessos rudimentares aos espaços de moradia, espaços de uso comunitário e atividades comerciais locais, que apresentam dificuldades para o acesso de coletores mecanizados. A coleta porta a porta, ou alternativas já utilizadas como a figura do gari comunitário, têm exigido o dimensionamento adequado dos equipamentos e da frequência do recolhimento do lixo para evitar acumulação dos RSU em qualquer estágio. Soma-se a isso a resistência de parte significativa de moradores que ainda descartam inadequadamente os diferentes tipos de resíduos e que comprometem a saúde pública.

Os RSU, por sua vez, demandam diversas classificações segundo o grau de periculosidade, em função de suas propriedades físicas, químicas e infectocontagiosas e identificação de contaminantes presentes em sua "massa". Mas existem também classificações em relação à fonte geradora, à capacidade de reaproveitamento $\mathrm{e}$ biodegradabilidade. São classificados pela ABNT, NBR 10.004 (ABNT, 2004) em função de sua periculosidade química e biológica e divididos em classes I - resíduos perigosos; classe II - resíduos não perigosos, subdivididos em A, não inertes, e em $B$, inertes. Os RSU são normalmente considerados como classe II-A e II-B, no caso de alguns tipos de resíduos de construção civil. Não se pode ignorar, contudo, que costumam haver todas as espécies de descarte entre eles. Podem ser observadas sobras de medicamentos, seringas com agulhas, pilhas e baterias, enfim, resíduos tipicamente perigosos que podem apresentar inflamabilidade, corrosividade, reatividade, toxicidade ou patogenicidade. Também é preciso sublinhar que a produção de RSU no Brasil, "[...] diferente dos RSU dos países mais industrializados, possui, em sua maioria, alto teor de matéria orgânica [...]" (Schueler et al., 2012, p. 33), chegando a percentuais entre $50 \%$ e $60 \%$.

\section{Os Resíduos Sólidos Urbanos observados nas favelas aqui estudadas}

De acordo com a fonte geradora, os RSU observados nas comunidades de baixa renda estudadas foram os de produção domiciliar, comercial, de atividades públicas, de vias públicas e construção civil. Observou-se que os resíduos gerados em domicílios residenciais são compostos por matéria orgânica e itens domésticos diversos. Até há bem poucos anos, os resíduos domiciliares eram considerados como de pequeno risco 
ambiental. Hoje, seja pela introdução de novos produtos na vida moderna, seja pelo maior conhecimento dos impactos de determinados materiais no ambiente, considera-se que os resíduos domiciliares são uma ameaça à integridade do meio ambiente e do ser humano. Embora em pequena quantidade possam ser observados no lixo doméstico pilhas e baterias, óleo de motor, tintas, pesticidas, embalagens de inseticida, solventes e produtos de limpeza, termômetros, lâmpadas, remédios. Tais resíduos têm efeitos negativos para a saúde e o ambiente. Ao lado disto, ressalta-se que a presença de microrganismos favorece a transmissão de doenças infectocontagiosas estabelecidas pela presença de seringas e fraldas descartáveis, lenços de papel, papel higiênico, curativos, preservativos etc. (Abrelpe, 2015).

Quanto aos resíduos gerados em estabelecimentos comerciais de pequeno porte e de prestação de serviços nas favelas analisadas, verificou-se uma composição variável de acordo com o tipo de atividade desenvolvida no local, tendo sido observados em quantidade considerável sacolas e caixas de papelão, resíduos de abatedouro, resíduos de pequenos mercados e padarias, salões de beleza, oficinas de eletrodomésticos (geladeira) e peças de automóvel. Nas vias públicas, mesmo com a limpeza realizada por varrição, foi possível verificar a presença de resíduos gerados por transeuntes que por elas se deslocam. Além de peças provenientes de bens 'inservíveis' como fogão, geladeira, colchão, móveis em geral, galhadas resultantes de podas internas etc., podem ser encontrados na maioria dessas comunidades resíduos provenientes de entulhos de construção civil de pequeno porte. Foram observadas diversas iniciativas de construção e reformas residenciais, gerando resíduos de demolição e construção, bem como material de construção a granel em frente de algumas residências, que pode ser espalhado pelas ruas por animais e chuva.

\section{Procedimentos metodológicos, resultados e discussão}

A metodologia adotada para a realização das pesquisas de campo utilizou-se da divisão do agrupamento em três grupos de favelas, por conta de problemas de segurança nas comunidades. Na medida em que as favelas possibilitavam a entrada de técnicos para efetuar os levantamentos de dados, os trabalhos eram executados e sistematizados. A partir da compreensão das fontes geradoras e classificação dos tipos de RSU foi possível traçar "cenários" para futura intervenção nesse campo disciplinar da infraestrutura urbana.

A realização desses estudos consistiu, inicialmente, em conhecer o processo de ocupação de cada uma dessas favelas, seus acessos e relação com o entorno, a dinâmica de funcionamento, os usos dos espaços coletivos e dos equipamentos sociais existentes, o perfil socioeconômico e cultural dos moradores, o levantamento do nível de organização, os serviços públicos existentes e a representatividade das lideranças locais. Essa abordagem social, somada aos levantamentos de informações formalmente disponíveis nos dados governamentais, permitiu identificar a maneira como os resíduos são gerados em cada comunidade e como os moradores lidam com essa questão ambiental.

A alta densidade habitacional e o baixo percentual relativo de áreas públicas, complementado pela inexistência ou pouca quantidade de vias carroçáveis, torna as comunidades de baixa renda locais extremamente difíceis em relação a disposição e coleta dos RSU. O pouco espaço e as más condições para dispor os descartes diários, temporariamente, no interior das moradias, favorece que sejam dispostos nas ruas logo que gerados, normalmente muito antes do recolhimento público ser feito. Assim, as já estreitas ruas (quando existem) recebem esse lixo, que fica exposto a chuva, animais e transeuntes.

No caso de comunidades situadas em encostas, a situação sanitária e ambiental tende a se agravar. A dificuldade do recolhimento junto com a necessidade de descarte muitas vezes leva o lixo para as encostas, 0 que aumenta a quantidade de vetores, contribui para a erosão do solo e reduz, ainda mais, a possibilidade de coleta.

Foram, também, observadas informações espaciais como a forma de disposição de resíduos pelas ruas, os pontos de acúmulo, as características viárias de largura, topografia, forma, utilização para estacionamento de veículos e todas as características importantes para o bom trânsito de equipamento de coleta de resíduos. Não foram observados catadores de lixo nas favelas visitadas. 0 Grupamento 1 é formado pelas favelas Chácara do Tanque, Amigos de Aerobita e Rua Albano n. 252; o Grupamento, 2 pelas comunidades Caxanga, Ladeira da Reunião, Morro da Reunião e José Braga; e o Grupamento 3, pela Fazenda do Mato Alto e Bela Vista do Mato Alto. A partir das investigações de campo 
foi possível adquirir dados quantitativos referentes a população, área, densidade habitacional e quantidade de domicílios, o que possibilitou estimar a geração de resíduos referentes às comunidades com base em $1 \mathrm{~kg} / \mathrm{hab} /$ dia (Web Resol, 2017).

A Tabela 1 apresenta a estimativa de geração de RSU em cada comunidade estudada, calculada a partir da quantidade de habitantes, e a estimativa de contêineres propostos. Foi utilizada a relação estimada de $1 \mathrm{~kg}$ de lixo igual a 4,35 litros de lixo para o cálculo da quantidade de contêineres. Observa-se que cada fração do RSU possui uma densidade diferente, o que torna o dimensionamento preciso da relação entre peso e volume de RSU, de modo generalizado, impossível. A partir dessas informações foi possível definir um plano de intervenção visando a melhor forma de descarte e coleta dos RSU, com garantia do acesso dos veículos de coleta, quando possível.

\section{Sobre o Grupamento 1}

Composto pelas comunidades Chácara do Tanque, Amigos de Aerobita e Rua Albano, o Grupamento 1 apresentou boas condições relativas à identificação e coleta de RSU. A Chácara do Tanque situa-se em área plana onde é possível, em pelo menos um dos logradouros, o acesso de caminhão de coleta de resíduos (Figura 1). É limitada pelos Rio Covanca e o Arroio Tindiba, com águas visualmente deterioradas. O traçado viário é composto, basicamente, por um anel que circunda a área, cortada por acessos perpendiculares. Toda a área é plana e a via principal - Travessa da Chácara - é carroçável, com largura que varia entre 5,40 e 7,00 metros, o suficiente para o trânsito e estacionamento de automóveis, inclusive de caminhão de coleta de lixo. As travessas perpendiculares são, em sua maioria, muito estreitas, servindo apenas a pedestres. Várias delas apresentam portão de entrada, sendo algumas muito estreitas e escuras como corredores residenciais.

A coleta de lixo é feita por caminhão, três vezes por semana, nas segundas, quartas e sextas-feiras e, às vezes, aos domingos. Eventualmente, funcionários da companhia de limpeza que moram na região têm o cuidado de "dar uma passada" para um recolhimento não oficial do lixo, pois estão conscientes da necessidade. Os comerciantes locais costumam não descartar seus resíduos em frente do seu comércio.

A partir de observação, os RSU são compostos por material orgânico (sobras de alimentos, resíduos de abatedouro e outros), papel e papelão (embalagens de alimentos, caixas, sacolas e outros), plásticos (duro, sacolas, PET e outros), garrafas de vidro, metais (embalagens), entre outros. Foram observados diversos pontos de descarte de Resíduos de Construção e Demolição (Classe II-B) devido a obras de reforma. Ao lado disso, é também na rua ou sobre marquises que são estocados agregados de construção civil para as obras.

O lixo é descartado de modo temporário em sacos plásticos dispostos em cantos e reentrâncias, ao longo da rua principal e em pontos de acúmulo. Foram observados dois pontos de acúmulo de resíduos

Tabela 1 - Estimativa de geraç̃o de resíduos sólidos urbanos

\begin{tabular}{|c|c|c|c|c|}
\hline Grupo & Comunidade & Densidade & $\begin{array}{l}\text { Estimativa de lixo } \\
\text { gerado - kg/dia }\end{array}$ & $\begin{array}{c}\text { Estimativa de contêineres o } \\
\text { serem distribuídos }\end{array}$ \\
\hline \multirow[t]{3}{*}{1} & Chácara do Tanque & $0,11 \mathrm{hab} / \mathrm{m}^{2}$ & 3.280 & 60 contêineres de 2401 + papeleiras \\
\hline & Amigos de Aerobita & $0,026 \mathrm{hab} / \mathrm{m}^{2}$ & 316 & 6 contêineres de $2401+$ papeleiras \\
\hline & Rua Albano n. 252 & $0,045 \mathrm{hab} / \mathrm{m}^{2}$ & 160 & 3 contêineres de $240 I+$ papeleiras \\
\hline \multirow[t]{4}{*}{2} & Caxanga & $0,04 \mathrm{hab} / \mathrm{m}^{2}$ & 462 & 8 contêineres de 2401 + papeleiras \\
\hline & Ladeira da Reunião & $0,028 \mathrm{hab} / \mathrm{m}^{2}$ & 1.412 & 26 contêineres de $2401+$ papeleiras \\
\hline & Morro da Reunião & $0,087 \mathrm{hab} / \mathrm{m}^{2}$ & 416 & 8 contêineres de 2401 + papeleiras \\
\hline & Vila José Braga & $0,008 \mathrm{hab} / \mathrm{m}^{2}$ & 96 & 2 contêineres de $240 I+$ papeleiras \\
\hline 3 & $\begin{array}{l}\text { Fazenda do Mato Alto e Bela } \\
\text { Vista Mato Alto }\end{array}$ & $0,053 \mathrm{hab} / \mathrm{m}^{2}$ & 10.556 & 15 Caixas Dumpster de $5 \mathrm{~m}^{3}$ \\
\hline
\end{tabular}

Fonte: autores. 


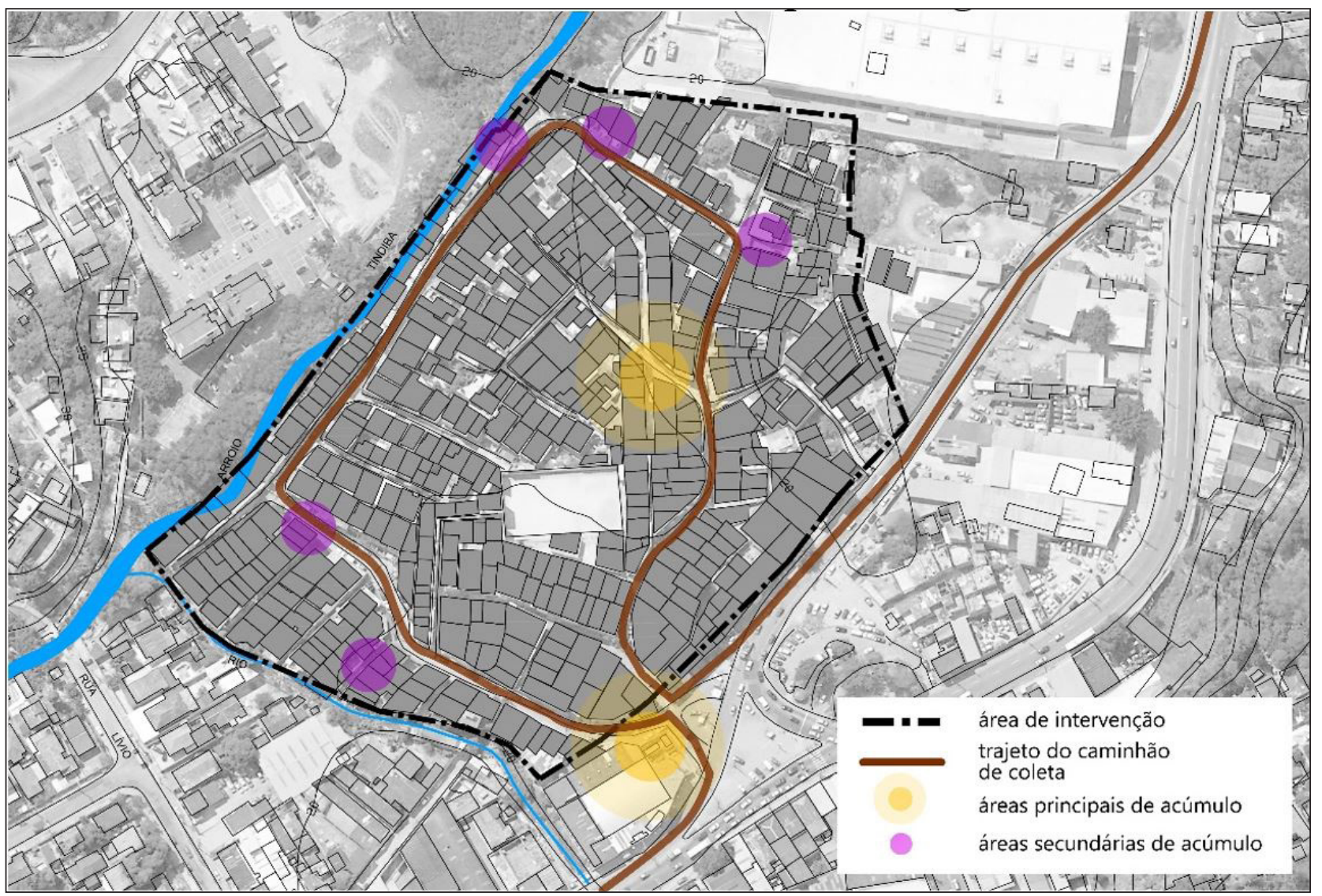

Figura 1 - Chácara do Tanque - Diagnóstico

Fonte: autores.

importantes, apresentados como pontos 1 e 2 na Figura 1. 0 ponto 1 , localizado na entrada da comunidade, local de fácil acesso para o caminhão de coleta. 0 ponto 2 , menos usado, localiza-se onde há um alargamento do acesso, porém afastado da passagem do caminhão. Não existem contentores de lixo, que é descartado em sacos plásticos, caixas ou sacolas de papel, sujeitos ao espalhamento pelo chão por animais.

A comunidade apresenta uma grande quantidade de estabelecimentos comerciais e, consequentemente, um grande volume de papel, papelão e resíduos de embalagem de modo geral. Foram distribuídas papeleiras para receber parte dos resíduos de papel. Nesse caso, recomenda-se a definição de um ponto para coleta de papel/papelão para os comerciantes na entrada da comunidade, próximo à Escola de Samba Renascer de Jacarepaguá. Esse papel poderá ser coletado pela Comlurb, no caso de coleta seletiva. Recomenda-se, também, o estímulo à criação de frentes de coletas seletivas por parte dos moradores, principalmente nas servidões em que há dificuldades para o recolhimento de resíduos através de caminhões.

Para essa comunidade, propõe-se a distribuição de 59 contêineres de 2401 para a coleta de resíduos em geral, ao longo das vias carroçáveis e em pontos determinados de coleta estacionária, normalmente em esquinas de vias inacessíveis para os caminhões de coleta - nestas vias, o trabalho de coleta será feito manualmente. A distribuição desses contêineres pode ser analisada em planta, na Figura 2. 0 sistema viário proposto permite a circulação de caminhão com caçamba compactadora com capacidade de $15 \mathrm{~m}^{3}$ de lixo, amplamente utilizado para coleta de resíduos pela Comlurb. Seu trajeto poderá ser analisado na mesma planta, na qual também são apresentados as diferentes bacias de contribuição de RSU, o trajeto proposto para o caminhão de coleta de RSU, os pontos de coleta de papel e papelão e os pontos com os contêineres.

A Comunidade Amigos de Aerobita localiza-se em morro, porém a topografia não é acidentada por demais. 


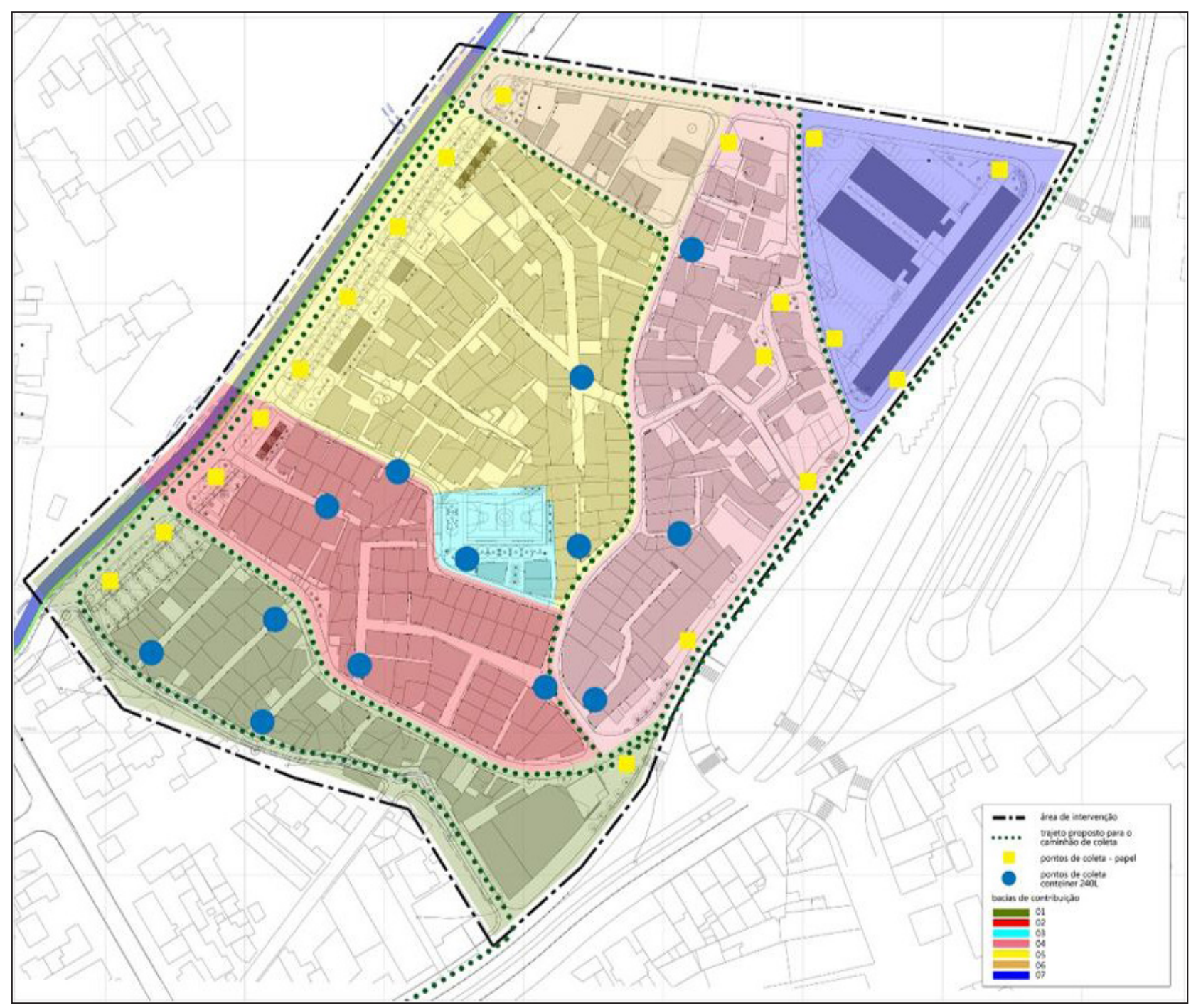

Figura 2 - Chácara do Tanque - Plano de intervenção para o manejo de resíduos sólidos Fonte: autores.

É composta, basicamente, por vias em formato "Y" (Figura 3). Parte da via principal é pavimentada com paralelepípedos e a outra parte é de terra batida, porem carroçável, com largura média de 7,00 metros, sendo possível o trânsito e estacionamento de automóveis. A coleta de lixo é feita três vezes por semana, nas $2^{\text {as }} 4^{\text {as }}$ e $6^{\text {as }}$-feiras. 0 recolhimento é feito de porta em porta, por caminhão que passa ao longo das ruas. Os moradores descartam cuidadosamente o lixo em sacos plásticos ao longo das duas vias dispostos no alto, pendurados em postes, portões etc., ou levam os sacos de lixo, pela escadaria, até a rua em que há coleta pública, na impossibilidade de acesso.

Foram observados dois pontos de acúmulo de resíduos importantes, apresentados como pontos 1 e 2 .
0 ponto 1, localizado em fração de terreno baldio. 0 ponto 2 , mais importante, ocorre em área de declive, vegetada. Segundo moradores, ocorre descarte de lixo feito por pessoas estranhas à comunidade. Na Figura 4 podem ser observadas as propostas para redistribuição dos pontos de acúmulo, com papeleiras e 12 contêineres de 240 litros, para suprirem dois dias sem coleta pública, bem como a identificação das bacias de contribuição de RSU.

A Comunidade Rua Albano (Figuras 5 e 6) é pequena e plana e a disposição e recolhimento dos RSU ocorrem sem dificuldades. A via é carroçável, com largura média de 5,00 metros, o suficiente para o trânsito de equipamento de coleta de lixo de pequeno porte. A coleta de lixo é feita três vezes 


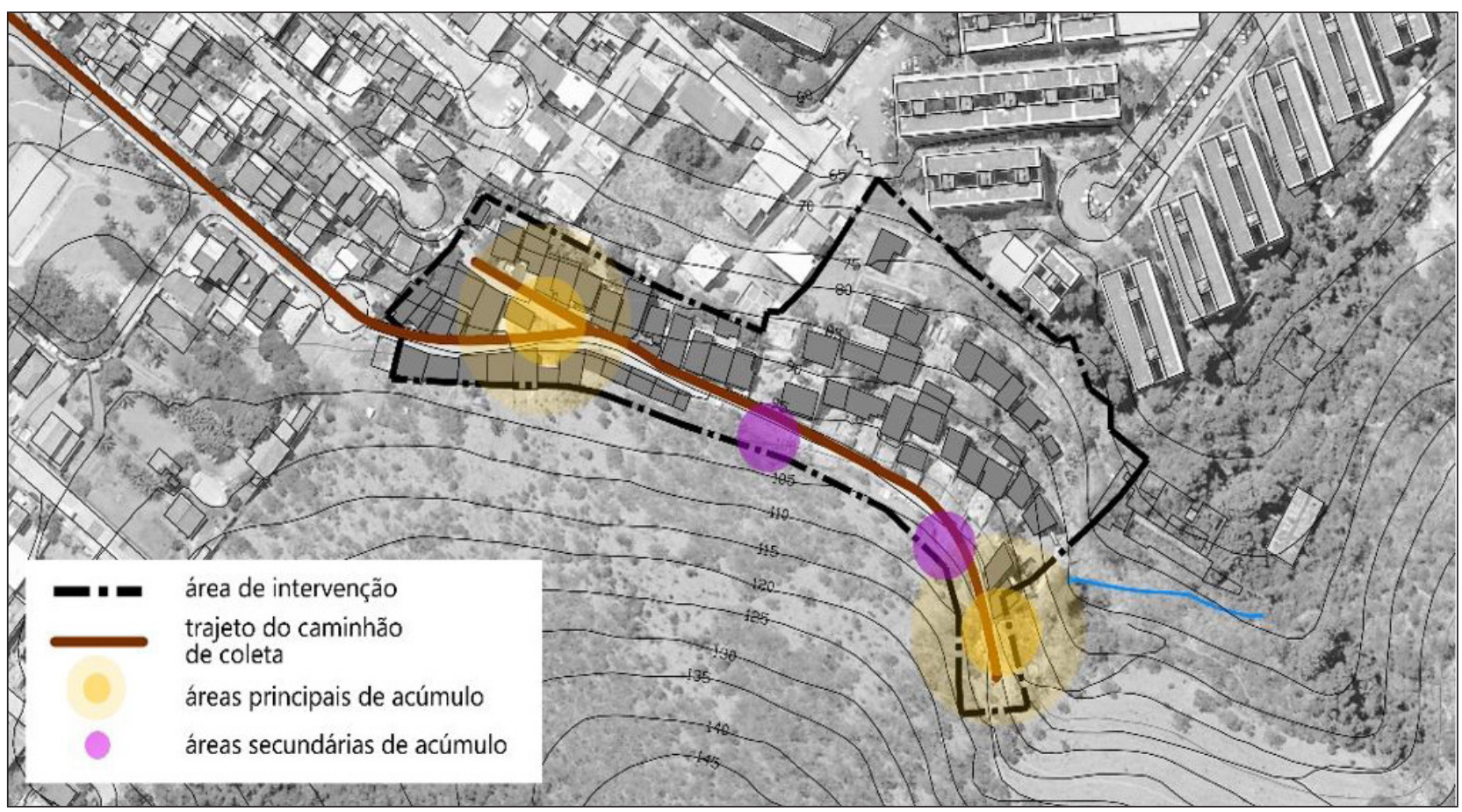

Figura 3 - Amigos da Aerobita - Diagnóstico

Fonte: autores.

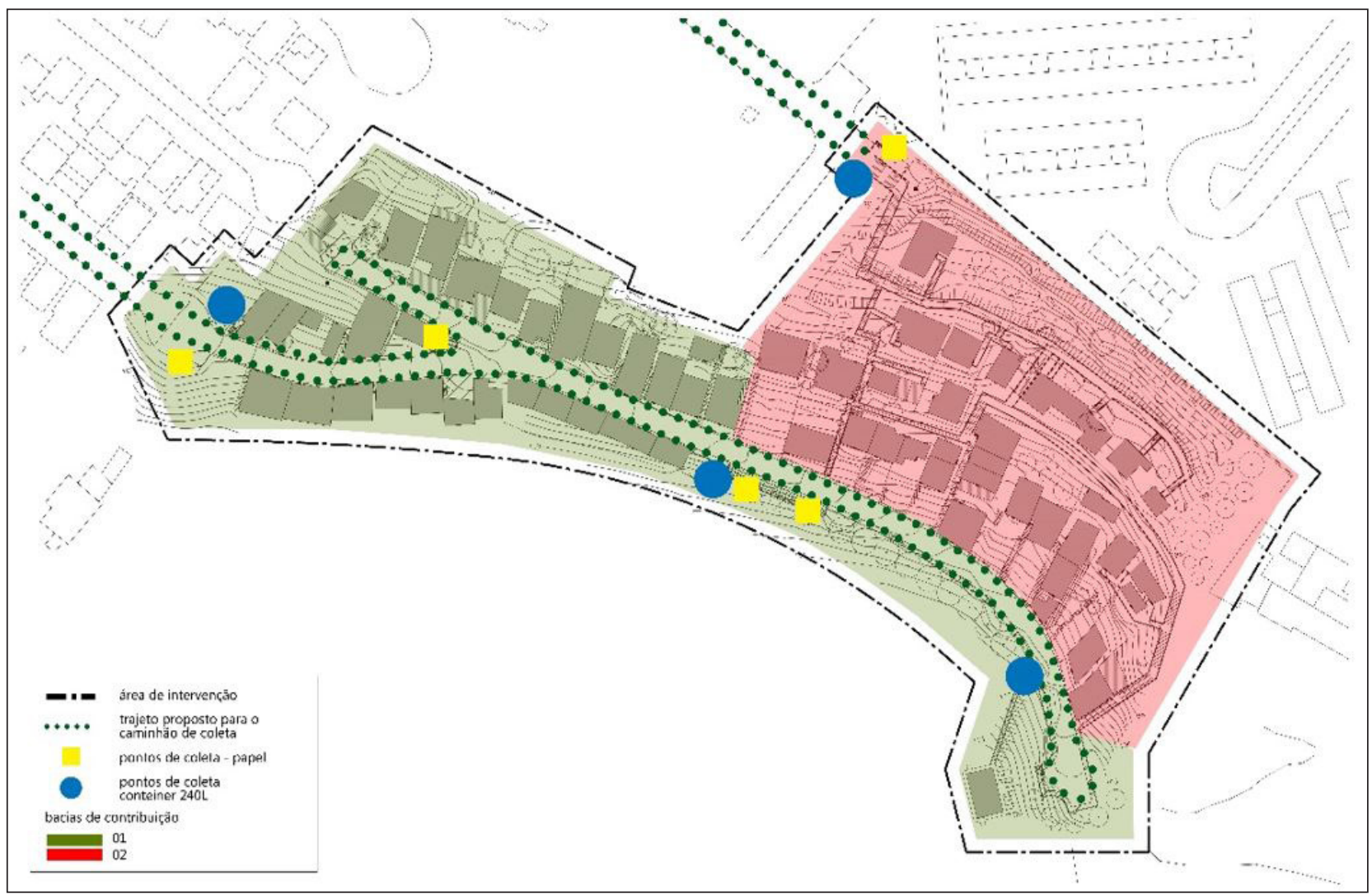

Figura 4 - Amigos da Aerobita - Plano de intervenç̃o para o manejo de resíduos sólidos Fonte: autores. 


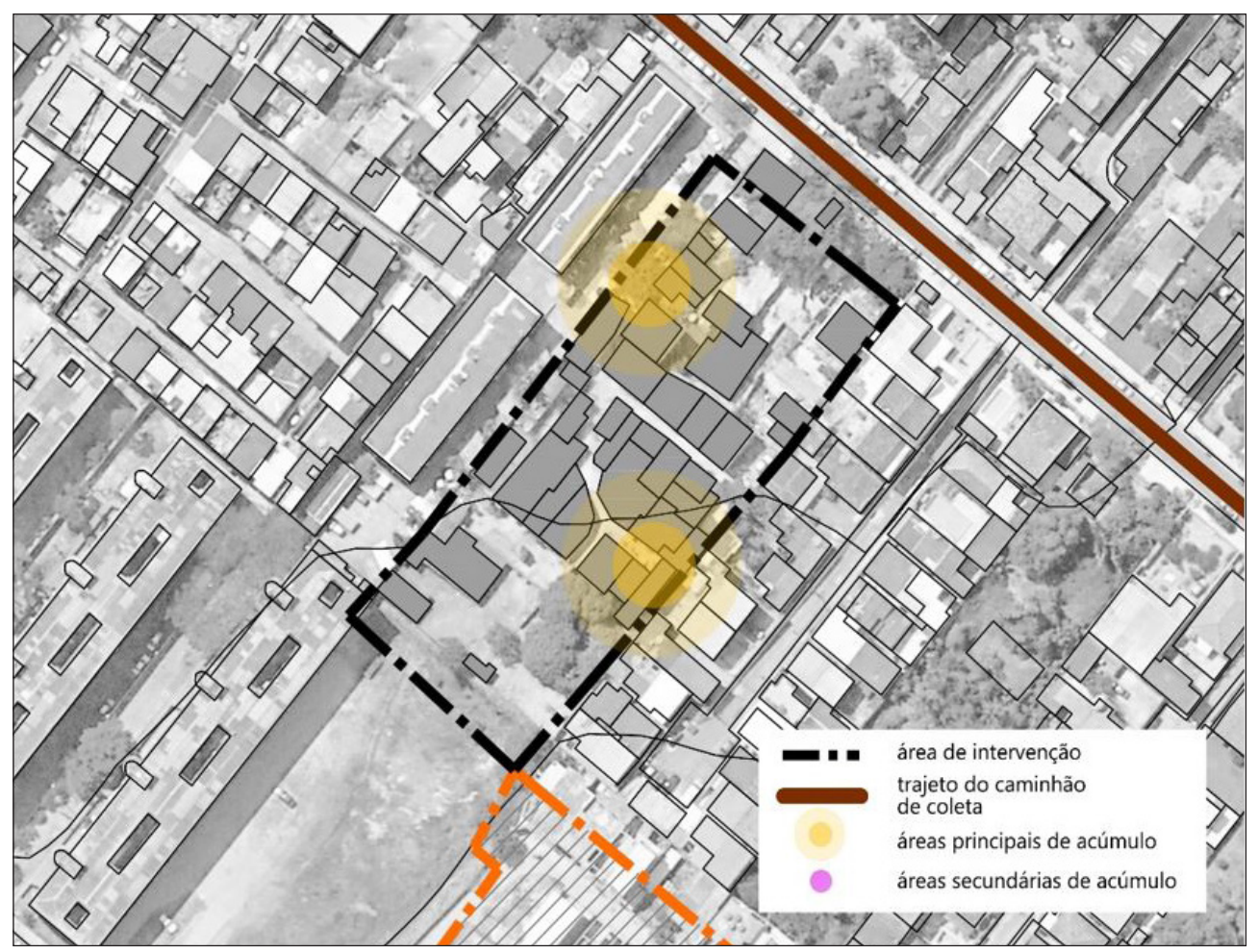

Figura 5 - Rua Albano n. 252 - Diagnóstico

Fonte: autores.

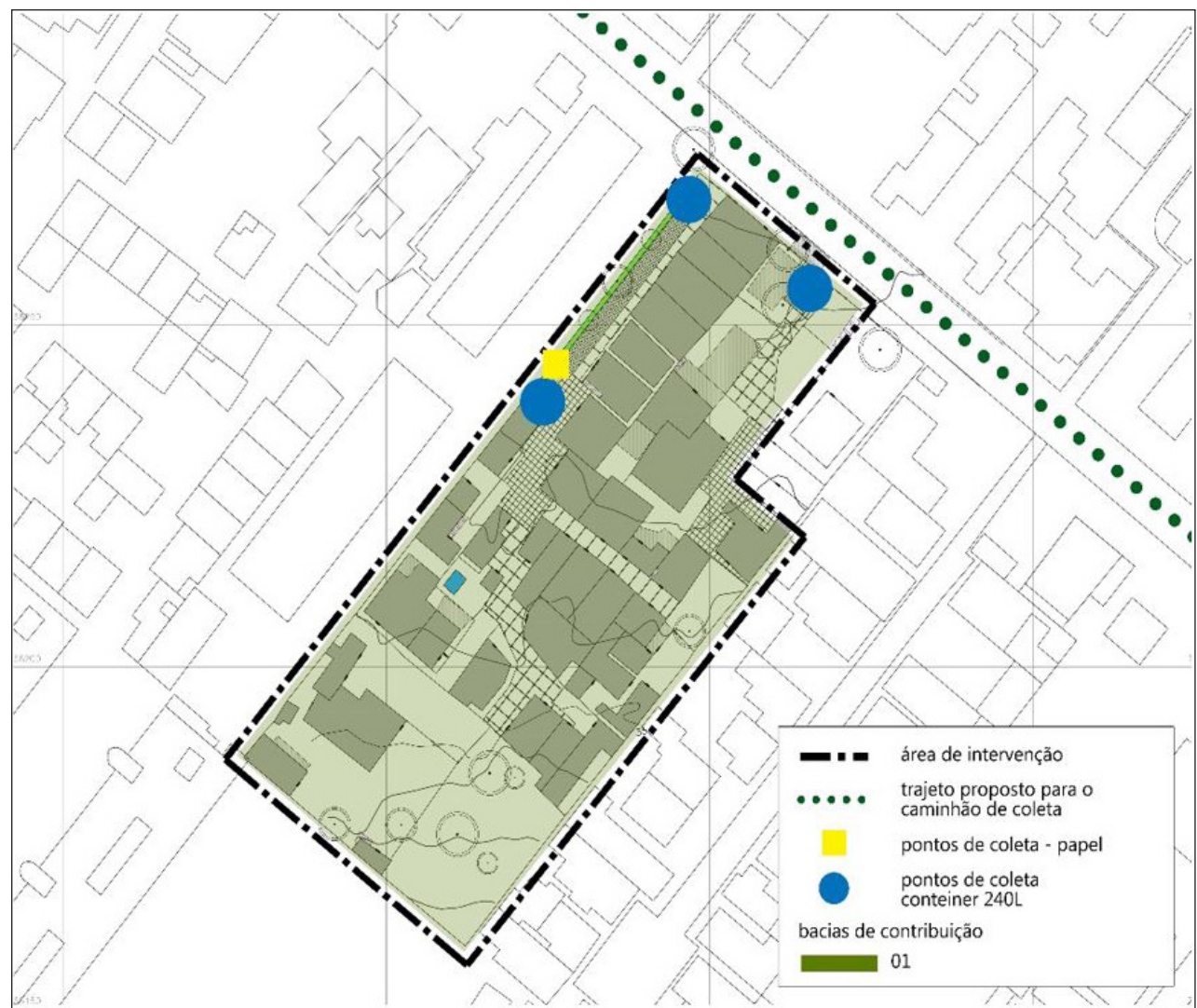

Figura 6 - Rua Albano n. 252 - Plano de intervenção para o manejo de resíduos sólidos Fonte: autores. 
por semana, nas segundas, quartas e sextas-feiras. Os moradores descartam o lixo em frente a suas casas. O lixo é descartado de modo temporário em sacos plásticos, que são levados pelo morador até o portão, e recolhidos pela coleta pública. Essa não recolhe os sacos dentro da vila.

A partir de observação, os RSU gerados são compostos por material orgânico (sobras de alimentos), papel e papelão (embalagens de alimentos, caixas, sacolas e outros), plásticos (duro, sacolas, PET e outros), garrafas de vidro, metais (embalagens), entre outros. Foram observados pontos de descarte de Resíduos de Construção e Demolição devido a obras e reformas.

Foram instituídos dois pontos de coleta estacionária com 6 contêineres de 240 litros para suprirem dois dias sem coleta pública, nos quais deverão ser dispostos os RSU em geral. Propõe-se a instalação de papeleira no pequeno largo previsto como oferta de área de convício. Não é possível circulação de caminhões e equipamentos no interior da comunidade. A Comlurb deverá realizar a coleta dos resíduos nos dois pontos de coleta situados na Rua Albano, na qual circula caminhão compactador com capacidade de $15 \mathrm{~m}^{3}$. Nessa comunidade também se recomenda a mobilização dos moradores para fazer a varrição dos espaços comuns a todos.

\section{Sobre o Grupamento 2}

Composto pelas comunidades Caxanga, Ladeira da Reunião, Morro da Reunião e José Braga. 0 traçado viário do grupamento principia pela Rua Elvira da Fonseca, que atravessa as comunidades e retorna pela Rua Nuporanga, paralela e próxima à primeira. As vias são em parte pavimentadas com paralelepípedos e em parte sem pavimentação, com terra batida, porém carroçável, com largura entre 4,50 e 5,00 metros, podendo haver trânsito e estacionamento de automóveis (Figura 7). A coleta de lixo é feita três vezes por semana, nas $2^{\text {as }}, 4^{\text {as }}$ e $6^{\text {as }}$-feiras, no início da manhã. 0 recolhimento é feito de porta em porta, por

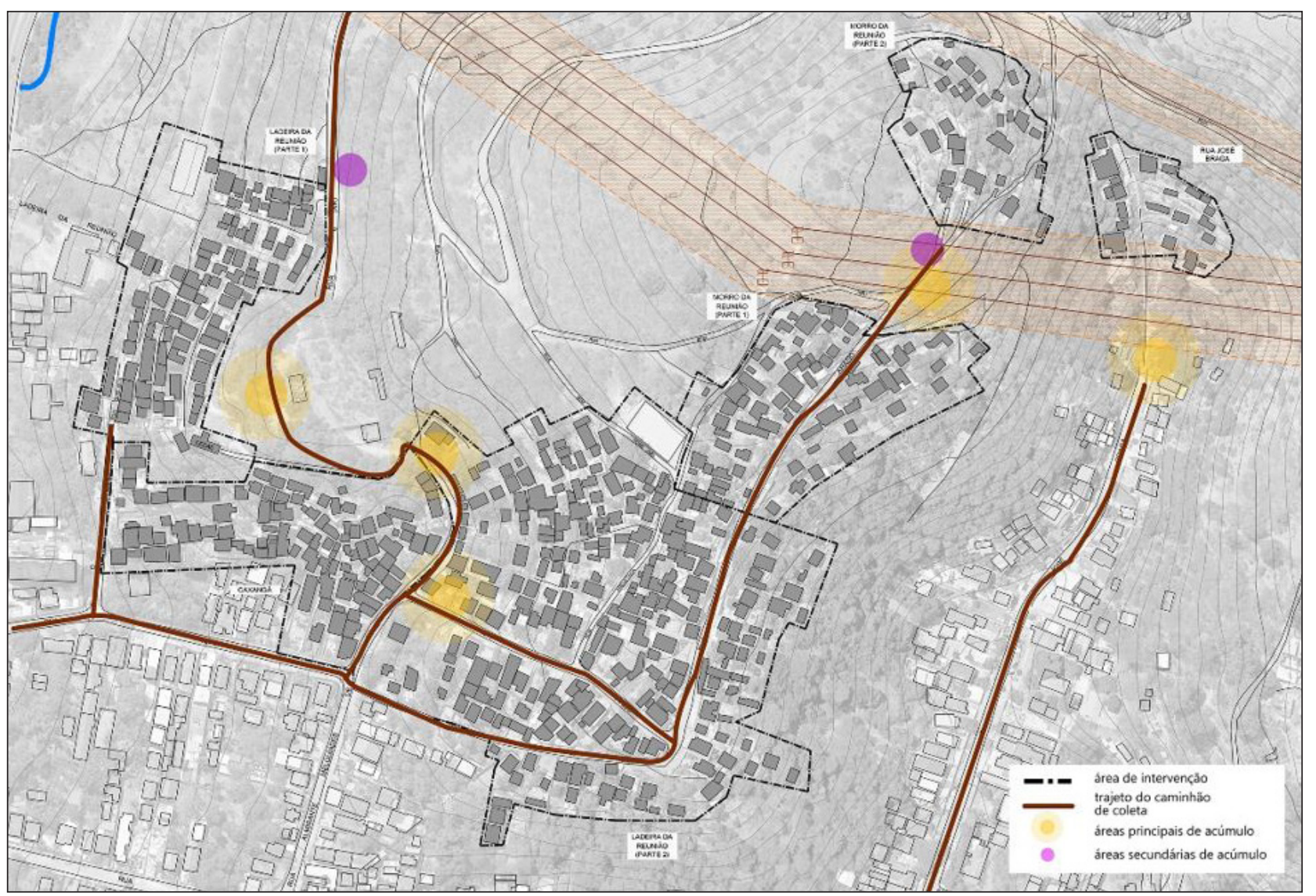

Figura 7 - Grupamento 2 - Diagnóstico

Fonte: autores. 
caminhão que passa ao longo das vias. Os moradores descartam o lixo em cantos pelas ruas ou levam para os pontos de acúmulo.

Foram observados dois importantes pontos de acúmulo de resíduos localizados em fração de terreno baldio e o nos arredores do reservatório da CEDAE (Figura 7). Existem dois pontos oficiais de recolhimento do lixo, identificados em campo. 0 lixo é descartado nos pontos de acúmulo observados ou de modo temporário em sacos plásticos ou mesmo fora de sacos, diretamente nas vias. Os sacos de lixo que ficam no chão são sujeitos ao espalhamento por cães e ao carreamento por chuva. Foram observados vestígios de queima de lixo.

Nessas comunidades do Grupamento 2 também se observou que os RSU gerados são compostos por material orgânico (sobras de alimentos, resíduos de abatedouro e outros), papel e papelão (embalagens de alimentos, caixas, sacolas e outros), plásticos (duro, sacolas, PET e outros), garrafas de vidro, metais (embalagens), entre outros. Foram observados diversos pontos de descarte de Resíduos de Construção e Demolição devido a obras de reforma.

Para essas comunidades, propõe-se a distribuição de 44 contêineres de 240 litros distribuídos em pontos de coleta e papeleiras. 0 sistema viário proposto permite a circulação de caminhão com caçamba compactadora com capacidade de $15 \mathrm{~m}^{3}$ de lixo, amplamente utilizado para coleta de resíduos pela Comlurb. Seu trajeto poderá ser analisado em planta (Figura 8).

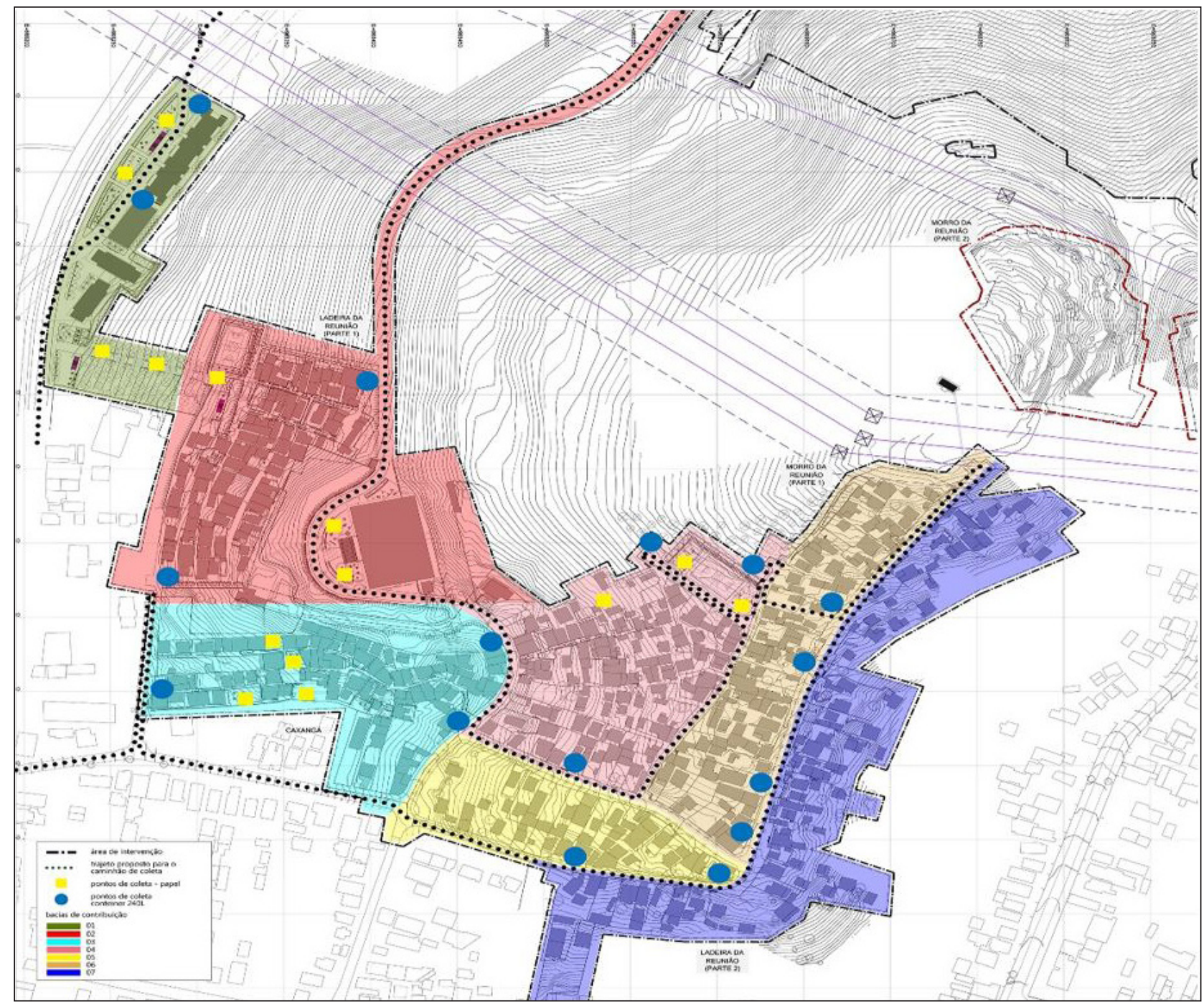

Figura 8 - Grupamento 2 - Plano de intervenção para o manejo de resíduos sólidos Fonte: autores. 


\section{Sobre o Grupamento 3}

Composto pelas comunidades Fazenda do Mato Alto e Bela Vista do Mato Alto (Figura 9). Trata-se de comunidades em encosta. A Fazenda do Mato Alto possui uma população estimada em 7.087 habitantes e a Bela Vista do Mato Alto, 3.496 habitantes, totalizando aproximadamente 10.583 habitantes (projeção 2020). Nesse caso, foi diagnosticado que a média de geração de resíduos é estimada em $1 \mathrm{~kg} / \mathrm{hab} /$ dia. 0 total de resíduos gerados estimados alcança $10.556 \mathrm{~kg} /$ dia. Cabe ressaltar, no entanto, que neste Grupamento 3 as visitas de campo foram interrompidas por diversas vezes por questões de segurança.

No diagnóstico foi apontado que os RSU gerados são compostos por material orgânico (sobras de alimentos, resíduos de abatedouro e outros), papel e papelão (embalagens de alimentos, caixas, sacolas e outros), plásticos (duro, sacolas, PET e outros), garrafas de vidro, metais (embalagens), entre outros. Foram observados diversos pontos de descarte de Resíduos de Construção e Demolição devido a obras de reforma, principalmente na área da Fazenda do Mato Alto.

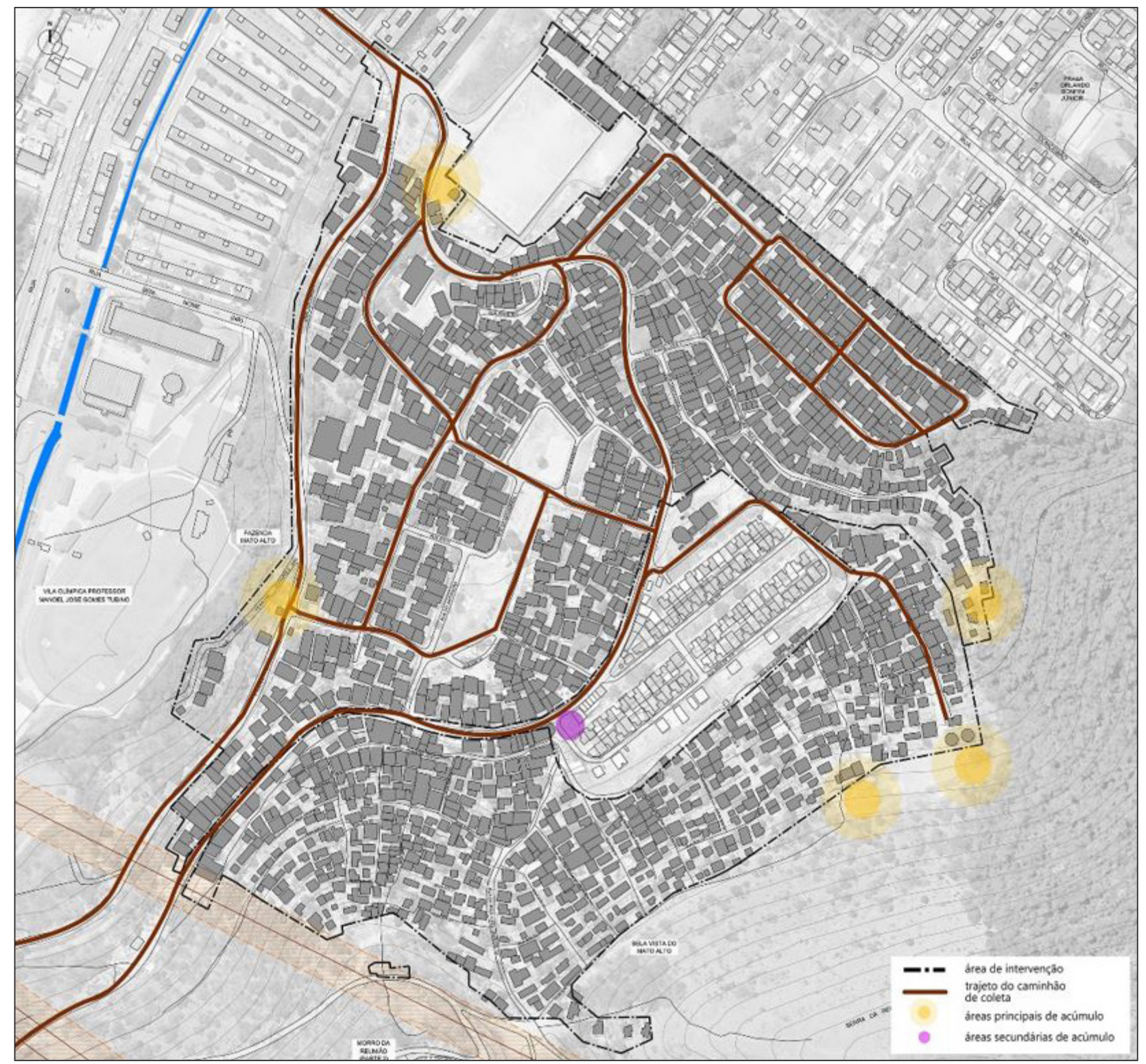

Figura 9 - Grupamento 3 - Diagnóstico

Fonte: autores. 


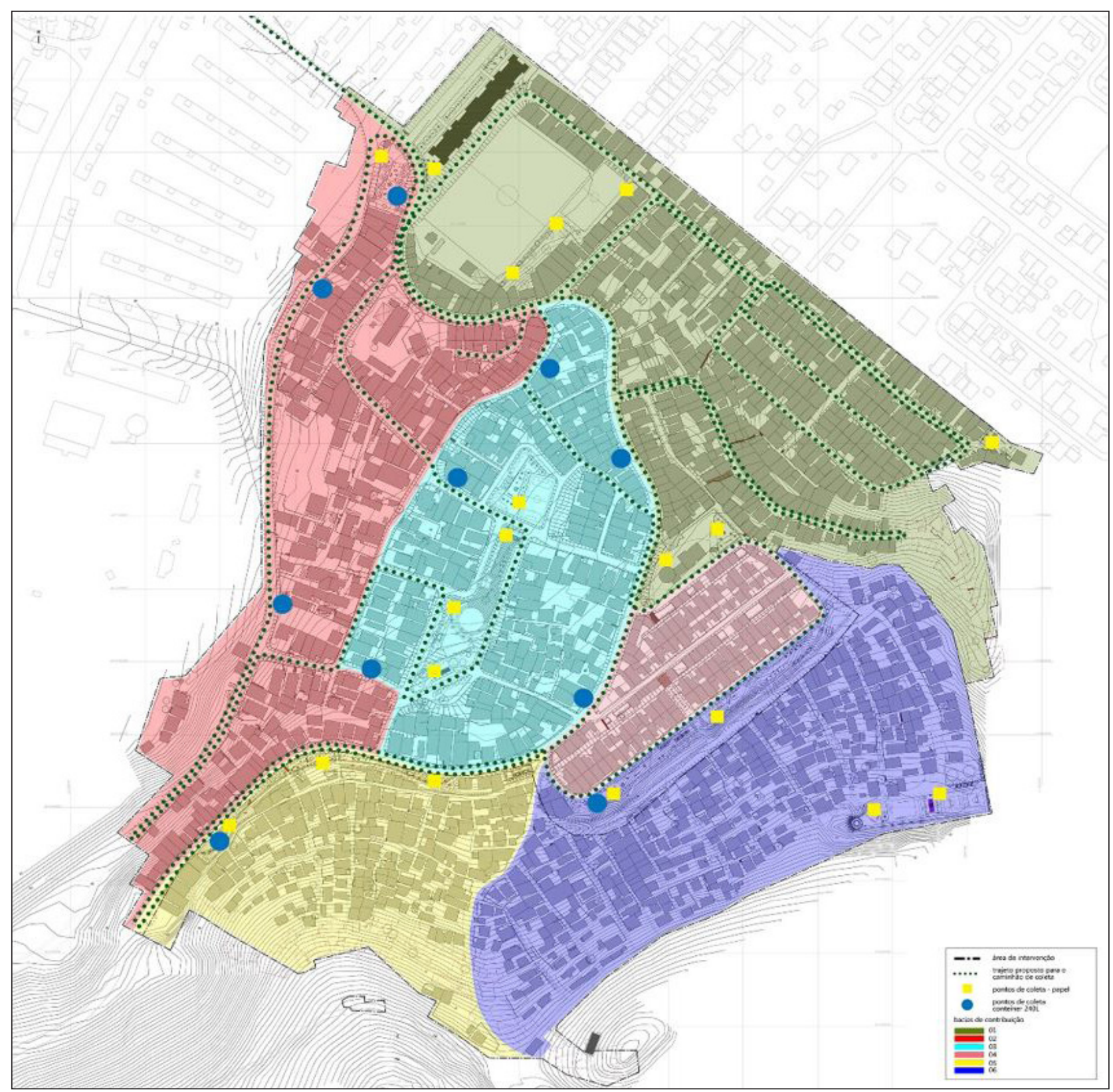

Figura 10 - Grupamento 3 - Plano de intervenção para o manejo de resíduos sólidos Fonte: autores.

Para essa comunidade, propõe-se a distribuição de 15 Caixas Dumpster de $5 \mathrm{~m}^{3}$ e papeleiras para a coleta de resíduos em geral (Figura 10), ao longo das vias carroçáveis e em pontos determinados de coleta estacionária, normalmente em esquinas de vias inacessíveis para os caminhões de coleta - nestas vias, o trabalho de coleta será feito manualmente. A distribuição desses contêineres pode ser analisada em planta. O sistema viário proposto permite a circulação de caminhão com caçamba compactadora com capacidade de $15 \mathrm{~m}^{3}$ de lixo, amplamente utilizado para coleta de resíduos pela Comlurb. Seu trajeto poderá ser analisado na mesma planta.

\section{Considerações finais}

É importante observar que os hábitos relacionados à disposição e manejo de RSU nas comunidades de baixa renda não são, necessariamente, diferentes dos 
de outros bairros da cidade, independentemente de classe social e das particularidades quanto à densidade urbana no espaço-favela. Ao lado disso, os acessos para equipamentos de limpeza são dificultados, em sua maioria, por acessos incompatíveis ou inexistência de vias de circulação que, com isso, impossibilitma ou dificultam a coleta pública.

Outro aspecto relevante é a presença de sacos de lixo dispostos no chão, sujeitos ao espalhamento por animais e ao carreamento por chuva, o que contribui para o entupimento de bueiros, criação de obstáculos para a drenagem pluvial, contaminação das águas e assoreamento das calhas dos rios urbanos, entre outros.

Nesse contexto urbano de favelas repletas de moradias de pequenas dimensões, em sua maioria com difíceis acessos e desprovidas de áreas externas, é desejável a possibilidade de coleta pública diária, para inibir o descarte inadequado dos resíduos. Diante desse quadro, a educação ambiental dos moradores das comunidades de baixa renda (e não apenas dessa parcela da cidade) apresenta-se como uma das alternativas para a conscientização socioambiental quanto à responsabilidade individual e coletiva diante da produção e manejo de RSU.

Espera-se que a coleta, o tratamento e a disposição final do lixo gerado pela população urbana sejam feitos de modo social e ambientalmente satisfatório, usando os meios mais econômicos possíveis, mas ainda existem muitos desafios que impedem que o processo ocorra do modo esperado, principalmente nas favelas. A disposição desses resíduos, seja temporária ou final, envolve aspectos ambientais, sanitários e questões associadas à saúde pública. 0 número crescente de substâncias identificadas como perigosas, junto com novos produtos orgânicos disponibilizados por indústrias, que ainda não passaram pelo teste do tempo e que não se pode realmente classificar como não perigosos e, ainda, o aumento de trabalhos informais e pequenas fábricas caseiras, que podem utilizar substâncias e/ou elementos considerados perigosos, tornam os RSU um material muitas vezes menos "inocente" do que o que é dito na norma, NBR 10.004 (ABNT, 2004), que os classifica como Classe II-A (resíduos não perigosos e não inertes). Observa-se que a PNRS aponta a implementação de sistemas de logística reversa, mediante retorno dos produtos após o uso. Certamente essa seria uma medida para reduzir a quantidade/volume dos RSU gerados nas favelas e, consequentemente, facilitar a sua coleta. Projetos de coleta seletiva na fonte, focados na dinâmica de cada comunidade, contribuiriam com a redução do volume de RSU a ser coletado. Tais programas, todavia, devem abarcar todo o município, sendo seu foco principal a redução de RSU no aterro sanitário. A utilização dos resíduos triados (na fonte ou em usinas de triagem) segue de acordo com a tecnologia. Havendo tecnologia de transformação desse material em algo útil e de valor, haverá a separação e, consequentemente, a redução do material a ser aterrado, a facilitação da coleta e até o enriquecimento das pessoas responsáveis pela separação do RSU. De acordo com Jucá (2014), reciclagem e compostagem, nos EUA, aumentaram $27,4 \%$, de 1960 a 2010 , ao mesmo tempo que o aterramento dos RSU em aterros sofreu redução de 39\% no mesmo período. Esse fato, junto com ocorrências em outros países do mundo, aponta para um crescimento das formas de destinação de RSU mais saudável do que o aterramento e, consequentemente, para a necessidade de uma gestão da coleta seletiva e reciclagem. No contexto de um esforço para a coleta seletiva na fonte ou triagem efetiva dos RSU numa usina, as propostas de urbanização das favelas, e das cidades, seria bastante diferente das apresentadas neste artigo.

Por fim, a produção de RSU representa um dos principais desafios a serem enfrentados pelo planejamento urbano nos dias atuais, em decorrência da dinâmica plural da cidade contemporânea e sua relação com o consumo de bens geradores de resíduos. A heterogeneidade da urbe e seus conflitos espaciais impõem a necessidade de incorporar nos processos de urbanização as redes de produção e as novas tecnologias como aspectos fundamentais na definição de metas que garantam a sustentabilidade como um dos requisitos para melhor qualidade de vida no ambiente construído. Nesse caso, o tratamento da questão dos resíduos sólidos urbanos se inscreve como parte significativa da infraestrutura urbana e da perspectiva de espaços urbanos mais saudáveis. Uma discussão mais aprofundada sobre a gestão de RSU nas favelas torna-se muito dificil quando são raras as informações sobre o tema. Espera-se que este artigo venha a contribuir com a divulgação da dificuldade de disposição e coleta dos RSU nesses espaços e, consequentemente, com algumas propostas de solução que vizem uma melhor qualidade de saneamento para uma parcela da população já tão fragilizada. 


\section{Agradecimentos}

Os autores agradecem à advogada e assistente social Flora El-Jaick Maranhão e às arquitetas e urbanistas Karyne Maranhão e Natália Oliveira por sua participação no projeto de urbanização dos grupamentos de favelas, a qual possibilitou o desenvolvimento deste trabalho.

\section{Referências}

Associação Brasileira das Empresas de Limpeza Pública e Resíduos Especiais - ABRELPE. (2015). Panorama dos resíduos sólidos no Brasil 2003 a 2015. São Paulo: ABRELPE. Recuperado em 1 de dezembro de 2016, de http://www. abrelpe.org.br/panorama_apresentacao.cfm

Associação Brasileira de Normas Técnicas - ABNT. (2004). NBR-10.004: Resíduos sólidos - Classificação. Rio de Janeiro: ABNT.

Brasil. (2001, 10 de julho). Lei n. 10.257, de 20 de julho de 2001. Estatuto da Cidade. Regulamenta os arts. 182 e 183 da Constituição Federal, estabelece diretrizes gerais da política urbana e dá outras providências. Brasília: Diário Oficial da União.

Brasil. (2010, 2 de agosto). Lei n. 12.305, de 2 de agosto de 2010. Institui a Política Nacional de Resíduos Sólidos; altera a Lei no 9605/98 e da outras providências. Brasília: Diário Oficial da União.

Jucá, J. F. T. (2014). Gestão das tecnologias para tratamento dos resíduos sólidos urbanos no Brasil. Recife: GRS/UFPE. Recuperado em 20 de abril de 2017, de http://www. ecosdasardenha2014.com.br/apresentacoes/2808/ Gestao_das_tecnologias_de_tratamento_dos_residuos_ solidos_urbanos_no_Brasil-Jose_Juca.pdf

Kzure-Cerquera, H. (2010). Limites e desafios para o urbanismo contemporâneo face às fragmentações, colisões e articulações do espaço da cidade. In H. Herbst (Org.), Dez Anos de Arquitetura na Rural: percursos e perspectivas (pp. 355-363). Seropédica: Editora da UFRRJ.

Kzure-Cerquera, H. (2014). A saúde da cidade sob suspeita. In C. B. Silveira, T. M. Fernandes, \& B. Pellegrini (Org.),
Cidades Saudáveis? Alguns olhares sobre o tema (pp. 3164). Rio de Janeiro: Editora Fiocruz.

Kzure-Cerquera, H., \& Racca, G. B. (2014). Favelas cariocas: recortes espaciais da desigualdade. In Anais do I URB FAVELAS - Seminário Nacional Sobre Urbanização de Favelas. Rio de Janeiro: UFRJ. Recuperado em 28 de novembro de 2016, de http://www.sisgeenco.com.br/sistema/urbfavelas/ anais/ARQUIVOS/GT1-131-121-20140702142145.pdf

Mendez, G. P. (2017). Avaliação da gestão municipal de resíduos sólidos através de indicadores ambientais (Dissertação de mestrado). Universidade Federal do Rio de Janeiro, Rio de Janeiro.

Monteiro, C., Karpinski, J. A., Kuhl, M. R., \& Morozini, J. F. (2017). A gestão municipal de resíduos sólidos e as ações de sustentabilidade: um estudo realizado em um município do centro oeste do Paraná urbe. Urbe. Revista Brasileira de Gestão Urbana, 9(1), 139-154. http://dx.doi. org/10.1590/2175-3369.009.001.ao010.

Phillip, A. Jr., Oliveira e Aguiar, A., Castilhos, A. B. Jr., \& Luzzi, D. A. (2012). Gestão integrada de resíduos sólidos. In A. Jardim, C. Yoshida, \& J. V. Machado Filho. Política nacional, gestão e gerenciamento de resíduos sólidos (pp. 229-244). Barueri: Manole.

Schueler, A., Mahler, C., \& Guião, R. (2012). Compostagem. In C. Mahler (Org.), Lixo urbano, o que voce precisa saber sobre o assunto (pp. 33-70). Rio de Janeiro: Reavan: FAPERJ.

Sistema Nacional de Informações sobre a Gestão dos Resíduos Sólidos - SINIR. (2016). Logística reversa (acordos setoriais). Recuperado em 18 de julho de 2016, de http:// sinir.gov.br/web/guest/logistica-reversa

Soares, E., \& Mahler, C. (2012). Características dos residents sólidos urbanos e poder calorifico. In C. Mahler (Org.), Lixo urbano, o que voce precisa saber sobre o assunto (pp. 21-32). Rio de Janeiro: Reavan/FAPERJ.

Web Resol (2017). Manual de gerenciamento integrado de resíduos sólidos. Recuperado em 3 de março de 2017, de http://www.resol.com.br/cartilha4/residuossolidos/ residuossolidos_3.php

Recebido Dez. 18, 2016

Aprovado Jun. 07, 2017 